\title{
Volatile organic compounds (VOCs) in soils
}

\author{
Heribert Insam • Martin S. A. Seewald
}

Received: 7 September 2009/Revised: 13 January 2010/Accepted: 15 January 2010/Published online: 13 February 2010

(C) The Author(s) 2010. This article is published with open access at Springerlink.com

\begin{abstract}
Soils may act as sources or sinks of volatile organic compounds (VOCs). Many of the formed VOCs are produced by microorganisms, and it would be a challenge to investigate soil microbial communities by studying their VOC profile. Such "volatilomics" would have the advantage of avoiding extraction steps that are often a limit in genomic or proteomic approaches. Abundant literature on microbially produced VOCs is available, and in particular novel detection methods allow additional insight. The aim of this paper was to give an overview on the current knowledge of microbial VOC emissions from soils.
\end{abstract}

Keywords Volatile organic compounds (VOC) .

Volatilomics $\cdot$ Communities

\section{Introduction}

During the last decades, soil microbiology underwent major changes. Initial attempts to understand the functioning of nutrient turnover by isolating organisms were followed by the age of activity measurements (enzymes, respiration). Following the trends in ecology, in the 1970s, soil microbiologists started to emphasize nutrient pools (microbial biomass) and fluxes until methods became available that were able to address more specific components of the community (Insam 2001). Specific structural components, like ergosterol or muramic acid, as well as phospholipid fatty acids (PLFAs), were successfully used to shed light on

H. Insam $(\bowtie) \cdot$ M. S. A. Seewald

Universitat Innsbruck,

Innsbruck, Austria

e-mail: heribert.insam@uibk.ac.at the composition of microbial communities. Finally, genome-based approaches were used for fingerprinting the soil microbiota down to the population level, like PCRdenaturing gradient gel electrophoresis (PCR-DGGE), amplified ribosomal DNA restriction analysis, singlestranded conformation polymorphism, T-RFLP, and several others. Today, approaches like pyrosequencing (Roesch et al. 2007) are targeting the metagenome. Soil genomics, soil proteomics, and soil metabolomics are not catchwords any more, but state of the art. However, even the most sophisticated analyses of genetic properties or compounds do have their own limitations, starting from obtaining representative samples (e.g., DNA extraction is usually based on samples of less than a gram) and quantitative extraction of the molecules from the soil matrix (RooseAmsaleg et al. 2001; Caldwell 2005; Bakken and Frostegard 2006; Pietramellara et al. 2009).

Similar to PLFAs, ergosterol, DNA, and other biomarkers, microorganisms are also responsible for producing microbial volatile organic compounds (mVOCs) in high diversity and quantity (e.g., Linton and Wright 1993; Isidorov and Jdanova 2002; Wheatley 2002; Leff and Fierer 2008) and for different purposes. Volatile organic compounds are available to the analyzer without tedious sample pretreatment and extraction, and for this reason, the measurement may not present biases, and might be of virtue compared to measurement of PLFAs, DNA, and other microbial biomarkers. The VOCs are commonly measured to characterize fungi, especially molds but also bacteria. Specific VOCs can be used to indicate fungal, bacterial, and other food spoilage (Börjesson et al. 1990, 1992; Bjurman et al. 1997; Kershi et al. 1998; Gao and Martin 2002; Mayr et al. 2003a), to characterize odor contamination in composting processes (Smet et al. 1999), or to detect mold growth in buildings (Wilkins et al. 2000; Fischer and Dott 
2003). Volatile organic compound analysis may represent a new emerging field, soil volatilomics.

In soils, VOCs are mainly produced by plants (Stotzky and Schenck 1976; Kesselmeier and Staudt 1999) and microorganisms (Stahl and Parkin 1976; Leff and Fierer 2008). Volatile organic compounds emitted by plant roots (and associated mycorrhiza) or seedlings were identified, and suggestions for their functions were proposed (Kesselmeier and Staudt 1999; Wenke et al. 2009). Interactions between plants and microbes mediated by VOCs as well as plant VOC production, measurement, and the influences of VOCs on plants have been discussed in several reviews (Stotzky and Schenck 1976; Linton and Wright 1993; Peñuelas and Llusià 2001; Cape 2003; Tholl et al. 2006) and are far beyond the scope of this review.

Due to their ubiquitous detectability and their information content, VOCs have been extensively studied aiming at different organisms, functions, and interactions since the last 90(!)years (e.g., Brown 1922 cited in Linton and Wright 1993). The scope of this review is to summarize the state of the art and latest advances in soil microbial VOC research, in particular since the excellent review by Stotzky and Schenck (1976).

\section{Effects of soil-related properties on VOC production and release}

Effects of soil-related properties on mVOC production

Investigation of soil VOC production is sophisticated as soil includes an enormous variability in parameters that influence $(\mathrm{mVOC})$ production. Besides differences in soil-specific community composition, mVOC production in soils is strongly depending on nutrient and oxygen availability and on the physiological state of the microorganisms. The availability of nutrients and oxygen itself is again depending on several environmental factors such as soil moisture, soil texture, or microbial activity (McNeal and Herbert 2009). The availability of oxygen is a basic parameter determining the types of VOCs produced as it allows highly effective respiration. Under aerobic conditions, energy is produced using almost any organic $\mathrm{C}$ source, which is then almost entirely evolved as $\mathrm{CO}_{2}$ and used for cell growth. Only small amounts are used for secondary metabolite production, some of them may also be VOCs.

Under micro-aerobic and anaerobic conditions, a larger fraction of $\mathrm{C}$ ends up as end products of (hetero- and) homofermentative processes (primary metabolic products). Thus, under anaerobic conditions, the diversity and amount of VOCs emitted is increased (Stotzky and Schenck 1976), as has been confirmed by Seewald et al. (2010).
Similarly, the substrate quality impacts the composition of VOCs produced (Stotzky and Schenck 1976). It is also important to note that even small variations in nutrient composition (e.g., nitrogen supply in form of $\mathrm{KNO}_{3}$ or $\left.\left(\mathrm{NH}_{4}\right)_{2} \mathrm{SO}_{4}\right)$ may change considerably the type and the amount of the individual VOCs produced (Wheatley et al. 1996, 1997).

As the $\mathrm{pH}$ value of soils impacts the nutrient availability for microorganisms and their physiological state it may affect VOC production (Stotzky and Schenck 1976). Also, soil temperature plays an important role in VOC production (Asensio et al. 2007a).

Effects of soil-related properties on VOC release

Apart from environmental factors that affect microorganisms and therefore the microbial VOC production, numerous factors impact VOC retention in soils, among them temperature, $\mathrm{pH}$, and moisture content (Brinton 1998). As the vapor pressures of the different VOCs are different and correspond with temperature (Schade and Custer 2004). The $\mathrm{pH}$ of soils determines the charge of any acidic or alkaline compound according to its isoelectric value, thus changing the evaporation pressure of these compounds. Assuming that most microbial VOCs are produced in the cell or are released from substrates that are digested by extracellular enzymes, these VOCs are produced in the liquid phase and are emitted only after the solution equilibrium is exceeded. The effect of water is not similar for all VOCs; in particular, polar compounds are more strongly retained than aromatic and aliphatic molecules (Ruiz et al. 1998). Asensio et al. (2007a) investigated VOC exchange rates and how they were influenced by soil moisture, temperature, and the presence of plant roots in a Mediterranean forest soil using proton transfer reactionmass spectrometry (PTR-MS) and GC-MS. They found soil to be a sink rather than a source of VOCs. Furthermore, their results pointed out that increases in soil temperature and decreases of soil water availability might enhance soil VOC emissions.

\section{Effects of VOC properties on VOC release}

Besides the availability of water (or other solvents and sorbents, see Chapter 4.3), the vapor pressure and the water solubility of VOCs affect the retention properties of all VOCs, which are defined as "organic compounds having at $293.15 \mathrm{~K}$ (i.e., $20^{\circ} \mathrm{C}$ ) a vapor pressure of $0.01 \mathrm{kPa}$ or more, or having a corresponding volatility under particular conditions of use" (EC Directive 1999). This definition includes members of many different chemical groups, thus showing a high variability in vapor pressure and water solubility, both depending on the physiochemical properties 
of the habitat. This dependence on environmental factors and the property-related differences between VOCs lead to biases. This was confirmed by a study that aimed to elucidate the effects of soil drought on $\mathrm{CO}_{2}$ and VOC exchange rates where, with changing soil moisture and temperature, different VOCs were emitted in changing ratios (Asensio et al. 2007a, b).

\section{Effects of adsorptive substances on VOC release}

In soils, most important is the action of adsorbents like clay minerals or humic acids. Ruiz et al. (1998) investigated the adsorption of $n$-hexane, $n$-heptane, $n$-octane, toluene, xylene, ethylbenzene, methyl ethyl ketone, and of water vapor on sand, clay, and limestone. They found considerable differences among the adsorption levels of the three soil minerals. Polar compounds were more strongly adsorbed than aliphatic and aromatic compounds. Serrano and Gallego (2006) investigated the effect of clay minerals and $C_{\text {org }}$ contents in acid and alkaline soils on the sorption of 25 VOCs. All compounds were adsorbed more strongly in alkaline than in acid soils. In alkaline soils, VOC sorption increased with $C_{\text {org }}$ content, while it decreased in acid soils. In acid soil, clay mineral (bentonite) played an important role in the sorption of VOCs. According to Aochi and Farmer (2005), the sorption/desorption behavior of VOCs must be seen in the context of soil texture and particle architecture. In their study, it was the soil physical properties that impeded the flow of both liquid and vapor phase within the pore network rather than chemical adsorption.

\section{Microorganisms and VOC production}

Microorganisms produce VOCs for different reasons. As already described above, highest amounts of VOCs are produced as metabolic end products of anaerobic fermentation processes. Also, the extracellular degradation of complex organic molecules or xenobiotics may result in the formation of VOCs that are lost before they can be absorbed and further degraded. At least some VOCs emitted from decomposing organic materials like leaf litter (Isidorov and Jdanova 2002; Leff and Fierer 2008) or organic waste (Mayrhofer et al. 2006) may originate from losses of such "almost-degraded" metabolites. But also the loss of intermediate products of metabolism is discussed. For example, members of the Cytophaga-FlavobacteriumBacteroides group that use valine, and others that use isoleucine for ketone biosynthesis, emit different ketones that serve as fatty acid precursor substances. These volatile intermediate products may be lost without any purpose (Dickschat et al. 2005a). Similarly, it is possible that other intermediate products especially metabolites of low molecular weight (e.g., isopropanol, isoprene, furan, etc.) reach the cell surface and escape from cytoplasm by diffusion. Future research in this direction could shed light on unknown aspects of microbial metabolism. Volatile organic compounds that are produced on purpose such as signaling substances are even more interesting as they are produced with high species specificity (see Chapter "Action potential of VOCs").

Production of mVOCs by microorganisms isolated from soil or similar habitats

Many investigations concerning soil microorganisms were performed under controlled conditions to overcome differences in $\mathrm{mVOC}$ production linked to heterogeneity of soil samples, differences in microbial community, and variability of soil properties. Most of the culturable soil microorganisms produce VOCs (Linton and Wright 1993), and it is assumed that similar mVOCs are the main contributors to total soil VOC production (Stotzky and Schenck 1976). Some VOCs are characteristically produced by specific phylogenetic groups or species and can therefore be used for taxonomic purposes (Larsen and Frisvad 1995a, c; Fischer et al. 1999). In a study on degrading household waste, high numbers of Lactococcus lactis were found to be correlating to certain VOCs. Measurement of the VOC emission pattern from a pure culture of $L$. lactis confirmed the positive correlations for butyric acid, dimethylsulfide, isoprene, and butanone (Mayrhofer et al. 2006). The investigation of VOCs excreted from Pseudomonas spp., Serratia spp., and Enterobacter spp. elucidated speciesspecific differences in dimethyldisulfide, dimethyltrisulfide, and isoprene production (Schöller et al. 1997). Schöller et al. (2002) screened 26 Streptomyces species and found a production of 120 different VOCs, among them isoprene, acetone, butanol, methyl propanol, methyl butenol, methyl butanol, cyclopentanone, dimethyldisulfide, dimethyltrisulfide, phenylethanol, and geosmin. Studies that investigated the VOC production from different bacterial species and mixed microbial communities of soil are listed in Table 1.

Like bacteria, also fungi produce a multitude of volatiles, some of which are common to several phylogenetic groups, while others seem to be unique for certain species (Larsen and Frisvad 1995a; Schnürer et al. 1999). Therefore, monitoring fungal metabolites can be used to detect fungal infestation. Larsen and Frisvad (1995a) investigated the VOC production of 47 different taxa within the genus Penicillium under different cultivation conditions. In total, 196 different volatile metabolites were characterized, among them isomeric sesquiterpene hydrocarbons $\left(\mathrm{C}_{15} \mathrm{H}_{24}\right)$, monoterpenes, alcohols, esters, ketones, alkenes, and a few aromatic compounds like geosmin and methyl isoborneol. 
Table 1 References of in vitro and in vivo VOC production from different bacterial and fungal species and of whole microbial communities living in soils or on organic materials

\begin{tabular}{|c|c|c|c|c|c|}
\hline Source & Year & Organisms investigated & $\begin{array}{l}\text { Habitat/cultivation } \\
\text { media }\end{array}$ & VOCs found & Method applied \\
\hline \multicolumn{6}{|l|}{ Bacteria } \\
\hline Alström & 2001 & $\begin{array}{l}\text { Different } \\
\text { Enterobacteriaceae, } \\
\text { Alcaligenes sp., } \\
\text { Stenotrophomonas } \\
\text { spp., Pseudomonas } \\
\text { spp., }\end{array}$ & $\begin{array}{l}\text { Rhizosphere isolates of } \\
\text { Verticillium dahliae, } \\
\text { cultivated on PDA }\end{array}$ & No VOC identified & $\begin{array}{l}\text { Petri dish detection } \\
\text { assay for herbicidal } \\
\text { activity }\end{array}$ \\
\hline Bunge et al. & 2008 & $\begin{array}{l}\text { Escherichia coli, } \\
\text { Shigella flexneri, } \\
\text { Salmonella enterica, } \\
\text { Candida tropicalis }\end{array}$ & Complex media & $\begin{array}{l}\text { Diverse VOCs, several } \\
\text { unidentified and some } \\
\text { identified compounds } \\
\text { of low molecular } \\
\text { weight }<150 \mathrm{u}\end{array}$ & PTR-MS \\
\hline Dickschat et al. & $2005 a$ & $\begin{array}{l}\text { Cytophaga- } \\
\text { Flavobacterium - } \\
\text { acterioides Group }\end{array}$ & $\begin{array}{l}\text { Maritime arctic strains } \\
\text { cultured on agar }\end{array}$ & $\begin{array}{l}\text { Diverse VOCs, mainly } \\
\text { methyl ketones }\end{array}$ & CLSA, GC-MS \\
\hline Duponnois and Kisa & 2006 & $\begin{array}{l}\text { Pseudomonas monteilii } \\
\text { HR13 }\end{array}$ & $\begin{array}{l}\text { Mycorrhizal bacterium, } \\
\text { cultivated on minimal } \\
\text { medium with different } \\
\text { C-sources }\end{array}$ & No VOC identified & $\begin{array}{l}\text { Petri dish detection } \\
\text { assay for antifungal } \\
\text { activity }\end{array}$ \\
\hline Farag et al. & 2006 & $\begin{array}{l}\text { Bacillus } \\
\text { amyloliquefaciens } \\
\text { IN937a, B. subtilis } \\
\text { GB03, E. coli } \\
\text { DH5alpha, } \\
\text { Pseudomonas } \\
\text { fluorescens 89B61 }\end{array}$ & Rhizosphere & $\begin{array}{l}\text { Diverse VOCs, } 10 \\
\text { identified, } 28 \text { not } \\
\text { characterized, } \\
\text { branched chain } \\
\text { alcohols }\end{array}$ & GC-MS, SPME \\
\hline Fernando et al. & 2005 & $\begin{array}{l}\text { Pseudomonas } \\
\text { fluorescens, } \\
\text { P. corrugata, } \\
\text { P. chlororaphis, } \\
\text { P. aurantiaca }\end{array}$ & $\begin{array}{l}\text { Isolated from canola } \\
\text { steem, soy bean plants, } \\
\text { cultivated on Luria } \\
\text { Bertani broth (LBB) }\end{array}$ & Fungistatic VOCs & GC-MS \\
\hline Fiddaman and Rossall & 1993 & Bacillus subtilis & $\begin{array}{l}\text { Several media (potato } \\
\text { dextrose Agar, PDA) }\end{array}$ & No VOC identified & $\begin{array}{l}\text { Petri dish detection } \\
\text { assay for antifungal } \\
\text { activity }\end{array}$ \\
\hline Hinton and Hume & 1995 & $\begin{array}{l}\text { Veillonella spp., } \\
\text { Bacterioides fragilis }\end{array}$ & $\begin{array}{l}\text { Cecal contents of adult } \\
\text { chicken, cultivated on } \\
\text { agar medium }\end{array}$ & No VOC identified & $\begin{array}{l}\text { Petri dish detection } \\
\text { assay for antibacterial } \\
\text { activity }\end{array}$ \\
\hline $\begin{array}{l}\text { Höckelmann and } \\
\text { Jüttner }\end{array}$ & 2004 & $\begin{array}{l}\text { Benthic cyanobacteria } \\
\text { (Calothrix, } \\
\text { Plectonema })\end{array}$ & $\begin{array}{l}\text { Cyanobacterial medium } \\
\text { (Jüttner et al., 1983) }\end{array}$ & $\begin{array}{l}\text { Limonene, } \\
\text { cyclohexanone, } \\
\text { straight chain } \\
\text { aldehydes }\end{array}$ & GC-MS \\
\hline Kai et al. & 2006 & $\begin{array}{l}\text { Stenotrophomonas } \\
\text { maltophilia } \text { R3089, } \\
\text { Serratia plymuthica } \\
\text { HRO-C48, Stenotro- } \\
\text { phomonas rhizophila } \\
\text { P69, Serratia odorifera } \\
\text { 4Rx13, Pseudomonas } \\
\text { trivialis 3Re2-7, S. } \\
\text { plymuthica 3Re4-18, } \\
\text { Bacillus subtilis } \\
\text { B2g, Pseudomonas } \\
\text { fluorescens L13-6-12, } \\
\text { Burkholderia } \\
\text { cepacia } 1 \mathrm{~S} 18\end{array}$ & $\begin{array}{l}\text { Rhizosphere isolates, } \\
\text { cultivated on NBII }\end{array}$ & $\begin{array}{l}\text { Diverse unidentified } \\
\text { VOCs }\end{array}$ & GC-MS \\
\hline Kai et al. & 2008 & $\begin{array}{l}\text { Stenotrophomonas } \\
\text { rhizophila } \text { P } 69 \text {, review } \\
\text { on several other VOC } \\
\text { producing bacteria }\end{array}$ & Batch culture & Diverse VOCs & GC-MS \\
\hline
\end{tabular}


Table 1 (continued)

\begin{tabular}{|c|c|c|c|c|c|}
\hline Source & Year & Organisms investigated & $\begin{array}{l}\text { Habitat/cultivation } \\
\text { media }\end{array}$ & VOCs found & Method applied \\
\hline Kai et al. & 2009 & $\begin{array}{l}\text { Bacillus subtilis B2g, } \\
\text { Burkholderia cepacia } \\
\text { 1S18, Pseudomonas } \\
\text { fluorescens L13-6-12, } \\
\text { Pseudomonas trivialis } \\
\text { 3Re2-7, Serratia } \\
\text { odorifera } 4 \mathrm{Rx} 13, \text { S. } \\
\text { plymuthica } 3 \mathrm{Re} 4-18, \text { S. } \\
\text { plymuthica } \text { HRO C48, } \\
\text { Staphylococcus } \\
\text { epidermidis } 2 \mathrm{P} 13-19 \text {, } \\
\text { Stenotrophomonas } \\
\text { maltophilia } \text { R3089, } \\
\text { S. rhizophila } \text { P69 }\end{array}$ & $\begin{array}{l}\text { Nutrient broth agar } \\
\text { plates }\end{array}$ & No VOC identified & $\begin{array}{l}\text { Petri dish detection } \\
\text { assay for antifungal } \\
\text { activity }\end{array}$ \\
\hline Liu et al. & 2008 & Bacillus subtilis G8 & $\begin{array}{l}\text { Soil isolate, cultivated } \\
\text { on agarose plates }\end{array}$ & $\begin{array}{l}\text { Diverse VOCs, alkyls, } \\
\text { alcohols, esters, } \\
\text { ketones, acid, amines, } \\
\text { oximes, phenols and } \\
\text { heterocyclic } \\
\text { compounds }\end{array}$ & SPME GC-MS \\
\hline Mackie and Wheatley & 1999 & Diverse bacteria & $\begin{array}{l}\text { Soil isolate, cultivated } \\
\text { on trpsone nutrient } \\
\text { broth (TSB) and } \\
\text { nutrient agar (NA) }\end{array}$ & No VOC identified & $\begin{array}{l}\text { Petri dish detection } \\
\text { assay for antifungal } \\
\text { activity }\end{array}$ \\
\hline Mayr et al. & $2003 a$ & $\begin{array}{l}\text { Pseudomonas spp., } \\
\text { Enterobacteriaceae, } \\
\text { lactic bacteria, } \\
\text { Enterococcus spp. }\end{array}$ & $\begin{array}{l}\text { Air and vacuum packed } \\
\text { meat (beef and pork) }\end{array}$ & $\begin{array}{l}\text { Diverse VOCs, several } \\
\text { unidentified and some } \\
\text { identified compounds } \\
\text { of low molecular } \\
\text { weight }<150 \mathrm{u}\end{array}$ & PTR-MS \\
\hline Peladan et al. & 1984 & Pseudomonas spp. & Certain culture medium & Volatile fatty acids & GLC \\
\hline Ryu et al. & 2003 & $\begin{array}{l}\text { Pseudomonas } \\
\text { fluorescens } 89 \mathrm{~B}-61, \\
\text { Bacillus pumilus T4, B. } \\
\text { pasteurii C-9, B. } \\
\text { subtilis (diverse tribes), } \\
\text { B. amyloliquefaciens } \\
\text { IN937a, Serratia } \\
\text { marescens 90-166, } \\
\text { Enterobacter cloacae } \\
\text { JM22 }\end{array}$ & $\begin{array}{l}\text { Rhizosphere isolates of } \\
\text { Arabidopsis thaliana, } \\
\text { cultivated on tryptic } \\
\text { soy agar plates }\end{array}$ & No VOC identified & $\begin{array}{l}\text { Effects on A. thaliana } \\
\text { growth }\end{array}$ \\
\hline Schöller et al. & 1997 & Gram-negative bacteria & $\begin{array}{l}\text { Minimal salt AB } \\
\text { medium (Clark } \\
\text { and Maaloe, 1976) }\end{array}$ & $\begin{array}{l}\text { Diverse VOCs, dimethyl } \\
\text { disulphide }\end{array}$ & GC-FID, GC-MS \\
\hline Schöller et al. & 2002 & $\begin{array}{l}\text { Actinomycetes ( } 26 \\
\text { Streptomyces spp.) }\end{array}$ & Yeast starch agar & $\begin{array}{l}\text { Diverse VOCs ( } 120 \\
\text { characterized), mainly } \\
\text { terpenoides }\end{array}$ & GC-FID, GC-MS \\
\hline Vergnais et al. & 1998 & Staphylococcus spp. & $\begin{array}{l}\text { PYS medium (Lechner } \\
\text { et al., 1988) }\end{array}$ & Diverse VOCs & SPME GC-MS \\
\hline Vespermann et al. & 2007 & $\begin{array}{l}\text { Stenotrophomonas } \\
\text { spp., Serratia spp., } \\
\text { Bacillus spp., } \\
\text { Pseudomonas spp., } \\
\text { Burkholderia cepacia, } \\
\text { Staphylococcus } \\
\text { epidermidis }\end{array}$ & & No VOC identified & $\begin{array}{l}\text { Effects on fungal and A. } \\
\text { thaliana growth }\end{array}$ \\
\hline Wilkins and Parkkalle & 1996 & $\begin{array}{l}\text { Actinomycetes } \\
\text { (7 isolates) }\end{array}$ & Medium (not described) & Diverse VOCs, & GC-MS \\
\hline Zhang et al. & 2007 & $\begin{array}{l}\text { Bacillus subtilis } \\
\text { (strain GB03) }\end{array}$ & Rhizosphere & No VOC identified & $\begin{array}{l}\text { Effects on A. thaliana } \\
\text { growth and gene } \\
\text { expression }\end{array}$ \\
\hline
\end{tabular}


Table 1 (continued)

\begin{tabular}{|c|c|c|c|c|c|}
\hline Source & Year & Organisms investigated & $\begin{array}{l}\text { Habitat/cultivation } \\
\text { media }\end{array}$ & VOCs found & Method applied \\
\hline Zou et al. & 2007 & $\begin{array}{l}328 \text { soil bacteria: } \\
\text { Alcaligenaceae, } \\
\text { Bacillales, } \\
\text { Micrococcaceae, } \\
\text { Rhizobiaceae, } \\
\text { Xanthomonadaceae }\end{array}$ & Soil bacterial isolates & Diverse VOCs & GC-MS \\
\hline \multicolumn{6}{|l|}{ Fungi } \\
\hline Bjurman et al. & 1997 & Penicillium & Pine wood & $\begin{array}{l}\text { 1-octene-3-ol, } \\
\text { 2-heptanone, } \\
\text { 4-allylanisole, } \\
\text { 3-methyl-1-butanol }\end{array}$ & $\begin{array}{l}\text { GC-ITD (ion trap } \\
\text { detector }\end{array}$ \\
\hline Börjesson et al. & 1990 & $\begin{array}{l}\text { Penicillium } \\
\text { aurantiogriseum }\end{array}$ & $\begin{array}{l}\text { Barley-, oat-, wheat } \\
\text { meal-, malt extract-, } \\
\text { Czapek- and Norkrans } \\
\text { agar }\end{array}$ & $\begin{array}{l}\text { Diverse VOCs, most } \\
\text { dominantly alcohols of } \\
\text { low molecular weight } \\
\text { and sesquiterpenes }\end{array}$ & GC-MS \\
\hline Börjesson et al. & 1992 & $\begin{array}{l}\text { Penicillium } \\
\text { brevicompactum, } \\
\text { P. glabrum, } P . \\
\text { roqueforti, Aspergillus } \\
\text { flavus, } \text { A. vesicolor, } \\
\text { A. candidus }\end{array}$ & Wheat and oat grains & Diverse VOCs & GC-MS \\
\hline Börjesson et al. & 1993 & $\begin{array}{l}10 \text { Penicillium spp., } \\
\text { Aspergillus spp. }\end{array}$ & Oatmeal agar & $\begin{array}{l}\text { Diverse VOCs, } \\
\text { including geosmin }\end{array}$ & GC-MS \\
\hline Christen et al. & 2000 & 4 Rhizopus spp. & $\begin{array}{l}\text { Cavassa bagasse, apple } \\
\text { pomace, soyabean, } \\
\text { amaranth grain and } \\
\text { soil bean oil }\end{array}$ & Diverse VOCs & $\begin{array}{l}\text { GC-FID, olfactory } \\
\text { sensation ( } 6 \text { persons) }\end{array}$ \\
\hline Demyttenaere et al. & 2004 & Fusarium spp. & MEA and PDA & $\begin{array}{l}\text { Sesquiterpenes, mainly } \\
\text { trichodiene }\end{array}$ & SPME/HSSE GC-MS \\
\hline Dickschat et al. & $2005 b$ & $\begin{array}{l}\text { Streptomyces } \\
\text { GWS-BW-H5 }\end{array}$ & $\begin{array}{l}\text { North sea water, } \\
\text { cultured on agar, } \\
\text { liquid culture }\end{array}$ & Diverse VOCs & GC-MS \\
\hline Ezra et al. & 2004 & Muscodor albus & $\begin{array}{l}\text { Soil, grown on potato } \\
\text { dextrose agar (PDA) }\end{array}$ & Diverse VOCs & GC-MS/PTR-MS \\
\hline Fiedler et al. & 2001 & $\begin{array}{l}4 \text { Aspergillus spp., } 2 \\
\text { Trichoderma spp., } 4 \\
\text { Penicillium spp., } \\
\text { Fusarium solani, } \\
\text { Mucor } \text { sp. }\end{array}$ & $\begin{array}{l}\text { Pure cultures cultivated } \\
\text { on, MEA, conifer } \\
\text { wood, beech wood, } \\
\text { YGC agar }\end{array}$ & $\begin{array}{l}\text { Diverse VOCs } \\
\quad(\text { more than 150) }\end{array}$ & HS-SPME GC-MS \\
\hline Fischer et al. & 1999 & $\begin{array}{l}\text { Aspergillus candidus, } \\
\text { A. fumigatus, } \text { A. } \\
\text { vesicolor, Emericella } \\
\text { nidulans, Paecilomyces } \\
\text { variotii, Penicillium } \\
\text { brevicompactum, } \\
\text { P. crustosum, } P . \\
\text { clavigerum, } P . \\
\text { cyclopium, } P . \\
\text { expansum, } P \text {. glabrum }\end{array}$ & $\begin{array}{l}\text { Airborne fungi, } \\
\text { cultivated on YES } \\
\text { agar }\end{array}$ & Diverse VOCs & GC-MS \\
\hline Fravel et al. & 2002 & $\begin{array}{l}\text { Sclerotinia minor, } S . \\
\text { sclerotium, } S . \text { rolfsii }\end{array}$ & $\begin{array}{l}\text { Lettuce and bean } \\
\text { isolates, cultivated on } \\
\text { PDA }\end{array}$ & Diverse VOCs & SPME GC-MS \\
\hline Gao and Martin & 2002 & Stachybotrys chartarum & Moist wood & Diverse VOCs & GC-MS \\
\hline Hynes et al. & 2007 & $\begin{array}{l}\text { Hypholoma fasciculare } \\
\text { Resinicium bicolor }\end{array}$ & $\begin{array}{l}\text { Wood decaying fungi, } \\
\text { cultivated on malt } \\
\text { broth }\end{array}$ & Diverse VOCs & HS-SPME GC-MS \\
\hline Kershi et al. & 1998 & $\begin{array}{l}4 \text { Eurotium spp., } \\
\text { Penicillium sp., } \\
\text { Wallemia sebi }\end{array}$ & $\begin{array}{l}\text { Food spoilage fungi, } \\
\text { grown as spore lawn } \\
\text { surface cultures on } \\
\text { milled wheat agar }\end{array}$ & No VOC identified & $\begin{array}{l}14 \text { polymer sensors } \\
\text { (EN) }\end{array}$ \\
\hline
\end{tabular}


Table 1 (continued)

\begin{tabular}{|c|c|c|c|c|c|}
\hline Source & Year & Organisms investigated & $\begin{array}{l}\text { Habitat/cultivation } \\
\text { media }\end{array}$ & VOCs found & Method applied \\
\hline Larsen and Frisvad & $1995 \mathrm{a}$ & Penicillium & YES agar & Diverse VOCs & GC-FID/ GC-MS \\
\hline Larsen and Frisvad & $1995 b$ & Penicillium vulpinum & Czapek agar & $\begin{array}{l}\text { Mono- and } \\
\text { sesquiterpenes }\end{array}$ & GC-MS \\
\hline Larsen and Frisvad & $1995 \mathrm{c}$ & 47 Penicillium spp. & $\begin{array}{l}\text { Czapec yeast autolysat } \\
\text { (CYA), MEA and YES } \\
\text { agar }\end{array}$ & $\begin{array}{l}\text { Diverse VOCs } \\
\text { (196 characterized, } \\
70 \text { identified })\end{array}$ & GC-MS/GC-FTIR \\
\hline Mattheis and Roberts & 1992 & Penicillium expansum & Czapek agar & Geosmin & GC-MS \\
\hline Matysik et al. & 2009 & $\begin{array}{l}3 \text { Penicillium spp., } 3 \\
\text { Aspergillus spp., } \\
\text { Cladosporium } \\
\text { cladosporoides }\end{array}$ & Dichloran glycerol agar & Diverse VOCs & GC-MS \\
\hline Minerdi et al. & 2008 & $\begin{array}{l}\text { Fusarium oxysporum } \\
\text { strain MSA } 35\end{array}$ & $\begin{array}{l}\text { Agar (as described in } \\
\text { experimental } \\
\text { procedures) }\end{array}$ & Diverse VOCs & $\begin{array}{l}\text { GC-MS/ growth } \\
\text { inhibition of bacterial } \\
\text { cultures }\end{array}$ \\
\hline Nilsson et al. & 1996 & 5 Penicillium spp. & YES agar & $\begin{array}{l}\text { Diverse VOCs } \\
\text { (17 identified) }\end{array}$ & HS-SPME GC-MS \\
\hline Pasanen et al. & 1996 & $\begin{array}{l}\text { Fusarium } \\
\text { sporotrichoides } \\
\text { (Sherbakoff), } \\
\text { Penicillium } \\
\text { verrucosum (Dierckx) }\end{array}$ & $\begin{array}{l}\text { Straw wheat and oat } \\
\text { grains }\end{array}$ & $\begin{array}{l}\text { Diverse VOCs } \\
\text { (12 identified) }\end{array}$ & GC-MS \\
\hline Spilvallo et al. & $2007 a$ & Truffle (3 Tuber spp.) & Fruiting bodies & Diverse VOCs & $\begin{array}{l}\text { Effects on A. thaliana } \\
\text { growth }\end{array}$ \\
\hline Spilvallo et al. & $2007 b$ & Truffle (3 Tuber spp.) & Fruiting bodies & $\begin{array}{l}\text { Diverse VOCs } \\
\text { (119 identified) }\end{array}$ & HS-SBSE GC-MS \\
\hline Strobel et al. & 2001 & Muscodor albus & $\begin{array}{l}\text { Endophytic fungus of } \\
\text { Cinnamonum } \\
\text { zeylanicum, cultivated } \\
\text { on PDA }\end{array}$ & $\begin{array}{l}\text { Diverse VOCs } \\
\text { (28 identified) }\end{array}$ & $\begin{array}{l}\text { GC-MS/ detection of } \\
\text { fungal (human and } \\
\text { plant pathogens) and } \\
\text { bacterial growth } \\
\text { inhibition }\end{array}$ \\
\hline Strobel et al. & 2007 & Muscodor albus E-6 & $\begin{array}{l}\text { Endophytic fungus of } \\
\text { Guazuma ulmifolia, } \\
\text { cultivated on PDA }\end{array}$ & Diverse VOCs & GC-MS \\
\hline Sunesson et al. & 1995 & Fungi (5 species) & $\begin{array}{l}\text { MEA and dichloran } \\
\text { glycerol agar }\end{array}$ & $\begin{array}{l}\text { Diverce VOCs } \\
\text { (57 identified) }\end{array}$ & GC-MC \\
\hline Wheatley et al. & 1997 & Trichoderma spp. & $\begin{array}{l}\text { Wood decaying fungi, } \\
\text { cultivated on MEA }\end{array}$ & $\begin{array}{l}\text { Diverse VOCs } \\
\text { (45 identified) }\end{array}$ & GC-MS \\
\hline Zeringue et al. & 1993 & $\begin{array}{l}\text { Aspergillus flavus } \\
\text { (8 strains) }\end{array}$ & Cultivated on PDA & $\mathrm{C} 15 \mathrm{H} 24$ compounds & GC-MS \\
\hline \multicolumn{6}{|l|}{ Communities } \\
\hline Asensio et al. & $2007 \mathrm{a}$ & Microbial community & Mediterranean soil & $\begin{array}{l}\text { Diverse VOCs } \\
\text { (31 identified) }\end{array}$ & PTR-MS/GC-MS \\
\hline Asensio et al. & $2007 b$ & Microbial community & Mediterranean soil & $\begin{array}{l}\text { Diverse VOCs } \\
\text { (24 identified) }\end{array}$ & PTR-MS/GC-MS \\
\hline Brinton & 1998 & Microbial community & Compost & Volatile organic acids & Total distillation, GC \\
\hline Leff and Fierer & 2008 & Microbial community & Different soils and litter & $\begin{array}{l}\text { Diverse VOCs } \\
\text { (17 identified })\end{array}$ & GC-MS \\
\hline Mayrhofer et al. & 2006 & Microbial community & Organic waste & various VOCs & PTR-MS \\
\hline McNeal and Herbert & 2009 & Microbial community & $\begin{array}{l}\text { Hyperthermic, } \\
\text { hypersaline soils }\end{array}$ & $\begin{array}{l}\text { Diverse VOCs } \\
\text { (72 identified) }\end{array}$ & GC-MS \\
\hline Seewald et al. & 2010 & Microbial community & $\begin{array}{l}\text { Temperate soil under } \\
\text { different compost load }\end{array}$ & $\begin{array}{l}\text { Diverse VOCs ( } 7 \\
\text { tentatively identified) }\end{array}$ & $\begin{array}{l}\text { PTR-MS/ PTR- } \\
\text { TOF-MS }\end{array}$ \\
\hline Serrano and Gallego & 2006 & Microbial community & $\begin{array}{l}\text { Different Mediterranean } \\
\text { soils }\end{array}$ & $\begin{array}{l}\text { Diverse VOCs } \\
(25 \text { identified })\end{array}$ & GC-MS \\
\hline Smet et al. & 1999 & Microbial community & $\begin{array}{l}\text { Aerobic and anaerobic } \\
\text { composting of } \\
\text { biowaste }\end{array}$ & Diverse VOCs & GC-FID \\
\hline
\end{tabular}


Table 1 (continued)

\begin{tabular}{|c|c|c|c|c|c|}
\hline Source & Year & Organisms investigated & $\begin{array}{l}\text { Habitat/cultivation } \\
\text { media }\end{array}$ & VOCs found & Method applied \\
\hline Stahl and Parkin & 1976 & $\begin{array}{l}\text { Actinobacteria, bacteria, } \\
\text { fungi }\end{array}$ & Soil & $\begin{array}{l}\text { Geosmin, } \\
\text { 2methylisoborneol, } \\
\text { other VOCs }\end{array}$ & \\
\hline Turan et al. & 2007 & Microbial community & Poultry litter compost & $\begin{array}{l}\text { Diverse VOCs } \\
\text { (25 identified and } \\
\text { quantified) }\end{array}$ & $\begin{array}{l}\text { Open path fourier } \\
\text { transform infrared } \\
\text { spectroscopy (FT-IR) }\end{array}$ \\
\hline Wang and $\mathrm{Wu}$ & 2008 & Microbial community & Orange waste & $\begin{array}{l}\text { Monoterpenes, isoprene, } \\
\text { other VOCs }\end{array}$ & $\begin{array}{l}\text { GC-MSD (mass } \\
\text { selective detector) }\end{array}$ \\
\hline Wheatley et al. & 1996 & Microbial community & Soil cropped to potatoes & $\begin{array}{l}\text { Diverse VOCs } \\
\text { (35 identified })\end{array}$ & GC-MS \\
\hline \multicolumn{6}{|l|}{ Reviews } \\
\hline $\begin{array}{l}\text { Kesselmeier and } \\
\text { Staudt }\end{array}$ & 1999 & $\begin{array}{l}\text { Review on VOCs } \\
\text { produced by plants }\end{array}$ & & & \\
\hline Linton and Wright & 1993 & $\begin{array}{l}\text { Review on microbial } \\
\text { VOCs }\end{array}$ & & & \\
\hline Schnürer et al. & 1999 & $\begin{array}{l}\text { Review on VOCs from } \\
\text { food spoiling fungi }\end{array}$ & & & \\
\hline Schulz and Dickschat & 2007 & $\begin{array}{l}\text { Review on bacterial } \\
\text { VOCs }\end{array}$ & & & \\
\hline Stotzky and Schenk & 1976 & $\begin{array}{l}\text { Review on VOCs from } \\
\text { microorganisms }\end{array}$ & & & \\
\hline Wheatley & 2002 & $\begin{array}{l}\text { Review on VOC } \\
\text { mediated bacterial and } \\
\text { fungal interaction }\end{array}$ & & & \\
\hline
\end{tabular}

More than half of the metabolites detected came from one species only, and nearly all taxa produced a unique profile of VOCs, demonstrating the potential of VOC profile analysis to be a useful tool in chemosystematics.

\section{Microbial VOCs from complex samples}

Only a few studies tried to characterize total VOC production of a complex habitat like soil. The effects of drought on interannual and seasonal soil VOC and $\mathrm{CO}_{2}$ exchange rates were studied finding that responses of individual monoterpenes and other VOCs were different depending on the compound (Asensio et al. 2007a, b). However, in that study, no microorganisms were identified, and therefore, VOCs produced could not be related to any species. In another study on the VOC production of 40 root-free soil and litter samples, 100 different VOCs could be detected, 70 of which were identified by GC-MS. Furfural and similar furan compounds were found to be produced in highest amounts. The presence of propanoic and butanoic acids was attributed to microbial fermentation. No specific microorganisms could, however, be related to any VOC produced (Leff and Fierer 2008). The effects of composts, mineral fertilizer, and combinations thereof on VOC production have been studied together with determination of microbial community structure by DGGE. Aerobic and anaerobic soil VOC emission was determined after glucose amendment using PTR-MS. Sewage sludge composts and mineral fertilization showed distinct effects on VOC production as well as on microbial community composition. VOC patterns were found to be able to discriminate among soil treatments, but specific tracer VOCs could not be identified (Seewald et al. 2010).

In future studies, combining characterization of microbial community structure by culturing and molecular biological methods with VOC measurements could help to elucidate the origin of different VOCs.

\section{Action potential of VOC}

\section{Interactions between bacteria, fungi, and plants mediated} through VOCs

Living organisms use VOCs as signaling substances to synchronize certain actions such as sporulation mediated by geosmin (Schöller et al. 2002) within an organism or a population or to impact other organisms living in the environment (Stahl and Parkin 1976). Thereby, VOCs can act on different physiological processes, e.g., inhibition of laccase activity of certain fungi by bacterial VOCs (Mackie and Wheatley 1999), or alteration of processes like nitrification (Wheatley et al. 1996; Ward et al. 1997; Paavolainen et al. 1998; Bending and Lincoln 2000) or nitrogen mineralization (Bremner and McCarty 1996; 
Smolander et al. 2006). Antagonistic interactions between different species are recognized by growth inhibition (Wheatley et al. 1997; Bending and Lincoln 1999; Wheatley 2002; Bruce et al. 2003; Chuankun et al. 2004; Fernando et al. 2005; Kai et al. 2006). The effects of some VOCs may be perceptible over long distance, such as the antagonistic VOC-mediated action of Fusarium oxisporum strain MSA 35 against other Fusarium wild types (Minerdi et al. 2008).

\section{Microbial volatile organic compounds as promoters and inhibitors of microbial and plant growth}

The VOCs produced by bacteria and by some fungi can impact other individuals (Stotzky and Schenck 1976; Wheatley 2002; Farag et al. 2006); VOCs emitted from Bacillus subtilis GB03, Bacillus amyloliquefaciens IN937a, and Enterobacter cloacae JM22 promoted the growth of Arabidopsis thaliana (Ryu et al. 2003; Zhang et al. 2007).

Besides these positive interactions, there are many inhibitions mediated by VOCs. A great variety of antibacterial VOCs are produced from plants (Dorman and Deans 2000), preventing them from direct bacterial attack and thus contributing to soil disease suppressiveness. Also, antifungal VOCs are contributing to soil disease suppressiveness (Fuchs et al. 2004) and are therefore investigated with great interest. A multitude of antifungal VOCs are emitted by bacteria (Mackie and Wheatley 1999; Wheatley 2002; Bruce et al. 2003; Chuankun et al. 2004; Kai et al. 2006; Zou et al. 2007; Liu et al. 2008). The repression of phytopathogens in soils through VOCs emitted by microorganisms (or even transgenic plants) may be a future alternative to conventional bactericides and fungicides and may help to reduce the health risk for consumers and farmers. Examples for fungistatic VOCs are 1-octen-3-ol, mono- and sesquiterpenes, nonanal acid, trimethylamine, and dimethyldisulfide which are produced by actinobacteria and bacteria of the genera Bacillus and Pseudomonas (Wilkins and Parkkalle 1996; Schöller et al. 1997; Chitarra et al. 2004). The VOC production from bacteria isolated from canola and soybean plants inhibits sclerotia and ascospore germination and mycelial growth of Sclerotinia sclerotiorum under laboratory as well as under field conditions. Benzothiazole, cyclohexanol, $n$-decanal, dimethyltrisulfide, 2-ethyl 1-hexanol, and nonanal were found to completely inhibit mycelial growth or sclerotia formation (Fernando et al. 2005).

On the other hand, some plants are negatively affected by VOCs emerging from soil; e.g., truffle (Tuber melanosporum) volatiles are able to inhibit the growth of $A$. thaliana, inducing an oxidative burst in A. thaliana leaf parenchyma tissue (Spilvallo et al. 2007a).

\section{Degradation of VOCs}

\section{Microbial degradation of VOCs}

Since in soils anaerobic and aerobic microhabitats coexist, end products of anaerobic metabolism serve as nutrients for aerobic microorganisms that finally produce $\mathrm{CO}_{2}$ and water (Owen et al. 2007). Many anaerobic microorganisms are able to degrade VOCs like formic or acetic acid (Krzycki and Zeikus 1984; Guyot and Brauman 1986). This metabolic pathway is well known from syntrophic methanogenic archaea. In methanogenic environments, saturated fatty acids, unsaturated fatty acids, alcohols, and hydrocarbons are degraded by the action of syntrophic communities. These syntrophic communities consist of an acetogenic and a methanogenic partner who cannot grow alone on a certain organic compound, but when present together, they can (Stams and Plugge 2009). The degradation of a syntrophic substrate is thermodynamically unfavorable if the product concentrations are at standard conditions (1 M concentration or $105 \mathrm{~Pa}$ for gases). The function of methanogens is to consume such products to lower their pressure $\left(10^{-4}-10^{-5} \mathrm{~atm}\right)$ to improve thermodynamic conditions. The diffusion distances for metabolite transfer should be minimal to ensure physical proximity of the syntrophic organisms (Stams and Plugge 2009). In their natural habitat, syntrophic propionate-degrading bacteria such as Syntrophobacter fumaroxidans form microcolonies with methanogens (Harmsen et al. 1998).

The removal of VOCs from airstreams, where VOCs often are contaminants, is a direct application of VOC degradation. Contaminated air is cleaned by microbes thriving in the biofilters and mineralizing VOCs (Malhautier et al. 2005). Volatile organic compounds are inaccessible to microorganisms as long as they stay in the gas phase. So the process of degradation has to start with the solubilization of contaminants in the liquid phase or after their adsorption to humic acid or clay mineral surfaces (polar and apolar interactions). The bioconversion of VOC pollutants to metabolic end- and intermediate products (VOCs), biomass, or carbon dioxide and water remains the second step. Malhautier et al. (2005) define working biofilters as a complex and structured ecosystem. Considering this, soils are perfect natural biofilters as they provide a multitude of species and microbial consortia (capable of different organic compound-degrading pathways), environmental conditions (from anaerobic to aerobic), and a variety of different VOC adsorbents (water, humic acids, clay minerals).

Physical-chemical degradation of VOCs

Little is known about abiotic VOC degradation processes in soils even though they seem to play an important role 
(Willson and Jones 1996). This lack of knowledge may be due to the inability to sterilize soils without directly impacting soil VOCs. Anyway, Atkinson and Arey (2003) give a very detailed overview on physical-chemical degradation of VOCs in the atmosphere where photolysis and spontaneous reactions with $\mathrm{OH}$ radicals (under the presence of light), $\mathrm{NO}_{3}$ radicals (under the absence of light), $\mathrm{O}_{3}$ (under the presence of light), and $\mathrm{Cl}$ atoms (at coastlines) are the main processes responsible for abiotic VOC degradation. Considering the fact that light can only reach habitats located in the soil surface (Woolley and Stoller 1977; Ciani et al. 2005), photolysis and other lightdriven reactions (with $\mathrm{OH}$ radicals and $\mathrm{O}_{3}$ ) only occur in a thin surface zone (Konstantinou et al. 2001). In this zone, $\mathrm{OH}$ radicals and $\mathrm{O}_{3}$ are produced by microorganisms or they diffuse from the atmosphere. As reactions with $\mathrm{Cl}$ atoms play a role in VOC degradation in air of coastal regions, it is likely that this process also works in soils that contain free $\mathrm{Cl}$ atoms. The degradation of VOC through $\mathrm{NO}_{3}$ radicals seems to be a rather plausible way of VOC degradation in soils. Nitrate is formed in soils under aerobic conditions (nitrification) and undergoes homolysis (formation of $\mathrm{NO}_{3}$ radicals) if exposed to light, whereas the reaction between VOCs and $\mathrm{NO}_{3}$ radicals does not need light (Konstantinou et al. 2001). Similarly, other powerful oxidants that are formed by microorganisms, like hydrogen peroxide, could also react with VOCs. Nevertheless, these free radicals and oxidants could react with substances other than VOCs (like humic acids or phospholipids) more often as the concentrations of VOCs are comparatively low. This again shows the interdependence of soil organic matter and clay contents with VOC emissions.

\section{Techniques for measuring VOCs}

\section{A new tool: PTR-MS}

Volatile compounds derive from biotic or abiotic sources, and depending on their chemical constitution, organic VOCs can be differentiated from inorganic compounds that are volatile, such as $\mathrm{CO}_{2}$ or $\mathrm{N}_{2}$. For VOC detection and quantification, different technologies are available. Among the newest technologies to detect VOCs is the PTR-MS which is a very sensitive technique (pptv level) that allows online VOC measurements (Hansel et al. 1995; Lindinger et al. 1998) and that may be combined with time-of-flight (TOF) for higher mass resolution and other methods like gas chromatography. The PTR-MS technique has so far been used for the detection of mVOCs in food quality control (Mayr et al. 2003a, b), organic waste decomposition (Mayrhofer et al. 2006), various soils (Schade and Custer 2004; Asensio et al. 2007a, b; Seewald 2008; Seewald et al.
2010), and for several other habitats (e.g., Kreuzwieser et al. 2002; Karl et al. 2003; Grabmer et al. 2004; Beauchamp et al. 2005). The main benefit of PTR-MS is its high sensitivity that allows online measurement of any air or gas sample.

The PTR-MS was used for investigating interannual and interseasonal influences on the VOC efflux rates of a Mediterranean holm oak forest, finding that soil is rather a VOC sink than a source (Asensio et al. 2007a) and that soil temperature and moisture strongly influence the VOC detection rate (Asensio et al. 2007b). Proton transfer reaction mass spectrometry was also used to identify the VOCs produced by Muscodor albus, a fungus producing antibacterial compounds in soils (Ezra et al. 2004) and to detect VOC emissions from an agricultural soil in northern Germany (Schade and Custer 2004).

Gas chromatography and mass spectrometry

A multitude of papers dealing with the microbial production of VOCs have been published so far. However, the number of VOCs is huge, and in any single publication, only a limited number of VOCs belonging to a few chemical groups can be considered. Most of the published papers describe the identification of VOCs, mainly polycyclic hydrocarbons or fatty acids, by head space or thermal desorption gas chromatography through different columns in combination with a detection by MS, flame ionization detector, flame photometric detector, infrared analyzer or photo ionization detector (Chung 2006). Soil microbial VOCs determined by GC-MS have been discussed in many publications (Mackie and Wheatley 1999; Schade and Custer 2004; Chuankun et al. 2004; Leff and Fierer 2008). Gas chromatography columns are selective for different chemical groups of VOCs and therefore incapable of total VOC estimation. Nevertheless, GC-MS is a valid and still the most common tool for VOC detection and identification. The combination of GCMS with PTR-MS would not only allow estimating total VOC production but also their identification. To get a higher mass resolution (two orders of magnitude), these methods can be expanded with TOF mass spectrometry to PTR-TOFMS. Another difference between PTR-TOF-MS and PTRMS is that with the TOF mass filter, the different velocities of the ions, due to the differences in their mass (with a mass resolution of $m / \Delta m=5,000$ ), can be determined at once, whereas with PTR-MS, mass abundances are measured sequentially.

Other methods

Besides mass spectrometric approaches, other methods were also applied to detect VOCs. Among them are microresp tubes detecting single volatile compounds (Kaufmann et 
al. 2005) and metal oxide-based olfactory sensors, so-called electronic noses (Rajamäki et al. 2005; Bastos and Magan 2007; Bruins et al. 2009) or nanoparticle-structured sensing array materials (Han et al. 2005).

\section{Uses in environmental ecology and future potential applications}

\section{Tracing organisms}

The steady improvement of gas GC-MS methods, electronic noses, TOF-MS, PTR-MS, and other techniques and the use of VOC fingerprints open novel perspectives in microbial ecology. Already now, volatile organic compounds are used to detect microbial contamination of air (Wilkins et al. 2000), drinking water (Wood et al. 1985, 2001), food (Schnürer et al. 1999; Mayr et al. 2003b; Kershi et al. 1998; Gao and Martin 2002; Börjesson et al. 1990, 1992), and medicine (Bruins et al. 2009). Several researchers focus on specific VOCs produced by specific organisms or study the effects of VOCs on organisms (Wilkins and Parkkalle 1996; Schöller et al. 1997, 2002; Ezra et al. 2004). Related to soils, the target is to be able to trace certain microorganisms by measuring specific VOCs or VOC patterns or to be able to infer how a soil has been treated, e.g., if and which type of compost or fertilizer had been applied (Seewald et al. 2010).

Volatile organic compound fingerprinting as a new, rapid tool in microbial ecology

Volatile organic compounds are produced in a high diversity in soils, some of them reflecting physiological properties or the presence of certain species. In different soils or under varying environmental conditions, the amounts and the type of VOCs produced may differ because of differences in community composition or nutrient availability (Wheatley et al. 1997). Determination of total VOC production or at least of a certain fraction results in VOC emission patterns or VOC fingerprints. Such VOC fingerprints may be used for different purposes, and in the future, they could give us information about the state of the soil. McNeal and Herbert (2009) also claim that VOCs are potential indicators for microbial community shifts and community composition in saline coastal upland areas, seasonal wetland, and grassland habitats within the Laguna Atascosa National Wildlife Refuge. They observed significant differences among several environmental factors (different organic substrate amendments, water availability, and soil texture) by GCMS identification of $72 \mathrm{VOC}$ metabolites and were able to show a correlation between VOC patterns and community- level physiological profiles and fatty acid methyl ester patterns, claiming the suitability of soil VOCs as indicators of soil microbial community structure over large spatiotemporal dynamics and environmental perturbations. Bastos (2007) was able to differentiate among soils and soil treatments employing an electronic nose, suggesting that such non-specific sensor arrays for headspace monitoring provide a rapid and noninvasive method for characterizing soil microbial activity, as influenced by environmental factors and nutrient inputs. In an extensive study, Leff and Fierer (2008) investigated 40 root-free soil and litter samples from different ecosystems and found that VOC production rates were correlated with microbial biomass and $\mathrm{CO}_{2}$ production levels, and it was suggested that VOCs may impact belowground ecology and should therefore be identified and investigated.

\section{Conclusion}

Volatile organic compounds from soils have been intensively investigated in the 1980s. The excellent review of Stotzky and Schenck (1976) summarizes the knowledge of that time which has not evolved very much until a few years ago. With newly available tools that even allow online monitoring, soil volatilomics are anticipated to have a bright future. The increasing knowledge on VOC emission patterns from specific organisms of different habitats and under different conditions, together with modern bioinformatics, may in the future allow monitoring the community structure, physiological state, and activity of any microbial community without the need of extraction or cultivation procedures. To achieve this, more studies aiming at the characterization of microorganisms by analyzing their VOC emissions will be necessary. Also, the investigation of the VOC output of microbial communities (from complex habitats such as soils) has to be strengthened to evolve VOC fingerprinting. Additionally, isolation of species from communities investigated and characterization of their VOC emissions under different conditions should be performed.

Even though VOCs from microorganisms are investigated since nearly one century, application of VOC analysis in microbial ecology still is in its infancy.

Acknowledgments We thank Hans van Veen and Paolo Nannipieri for the invitation to write this review. The FWF grant P189580 supported our work in this field.

Open Access This article is distributed under the terms of the Creative Commons Attribution Noncommercial License which permits any noncommercial use, distribution, and reproduction in any medium, provided the original author(s) and source are credited. 


\section{References}

Alström S (2001) Characteristics of bacteria from oilseed rape in relation to their biocontrol activity against Verticillium dahliae. $\mathrm{J}$ Phytopathol 149:57-64

Aochi YO, Farmer WJ (2005) Impact of soil microstructure on the molecular transport dynamics of 1,2-dichloroethane. Geoderma 127:137-153

Asensio D, Penuelas J, Filella I, Llusià J (2007a) On-line screening of soil VOCs exchange responses to moisture, temperature and root presence. Plant Soil 291:294-261

Asensio D, Penuelas J, Llusià J, Ogaya R, Filella I (2007b) Interannual and interseasonal soil $\mathrm{CO}_{2}$ efflux and $\mathrm{VOC}$ exchange rates in a Mediterranean holm oak forest in response to experimental drought. Soil Biol Biochem 39:2471-2484

Atkinson R, Arey J (2003) Atmospheric degradation of volatile organic compounds. Chem Rev 103:4605-4638

Bakken LR, Frostegard A (2006) Nucleic acid extraction from soil. In: Nannipieri P, Smalla K (eds) Soil biology volume 8 nucelic acids and proteins in soil. Springer, Heidelberg, pp 49-73

Bastos AC (2007) Microbial volatile fingerprints: potential use for soil/water diagnostics and correlation with traditional microbial parameters. Dissertation, Cranfield University, Faculty of Medicine and Biosciences, pp 1-308

Bastos AC, Magan N (2007) Soil volatile fingerprints: use for discrimination between soil types under different environmental conditions. Sensor Actuator B-Chem 125:556-562

Beauchamp J, Wisthaler A, Hansel A, Kleist E, Miebach A, Niinemets Ü, Schurr U, Wildt J (2005) Ozone induced emissions of biogenic VOC from tobacco: relationships between ozone uptake and emission of LOX products. Plant Cell Environ 28:1334-1343

Bending GD, Lincoln SD (1999) Characterisation of volatile sulphurcontaining compounds produced during decomposition of Brassica juncea tissues in soil. Soil Biol Biochem 31:695-703

Bending GD, Lincoln SD (2000) Inhibition of soil nitrifying bacteria communities and their activities by glucosinolate hydrolysis products. Soil Biol Biochem 32:1261-1269

Bjurman J, Nordstrand E, Kristensson J (1997) Growth-phase-related production of potential volatile-organic tracer compounds by moulds on wood. Indoor Air 7:2-7

Börjesson T, Stollman U, Schnürer J (1990) Volatile metabolites and other indicators of Penicillium aurantiogriseum growth on different substrates. Appl Environ Microb 56:3705-3710

Börjesson T, Stollman U, Schnürer J (1992) Volatile metabolites produced by six fungal species compared with other indicators of fungal growth on cereal grains. Appl Environ Microb 58:25992605

Börjesson TS, Stöllman UM, Schnürer JL (1993) Off-odorous compounds produced by molds on oatmeal agar: identification and relation to other growth characteristics. J Agr Food Chem 41:2104-2111

Bremner JM, McCarty GW (1996) Inhibition of nitrification in soil by allelochemicals derived from plants and plant residues. Soil Biol Bioch 8:181-218

Brinton W (1998) Volatile organic acids in compost: production and odorant aspects. Compost Sci Util 6:75-82

Bruce A, Steward D, Verrall S, Weathley RE (2003) Effect of volatiles from bacteria and yeast on the growth and pigmentation of sapstain fungi. Int Biodeter Biodegr 51:101-108

Bruins M, Bos A, Petit PLC, Eadie K, Rog A, Bos R, van Ramshorst GH, vanBelkum A (2009) Device-independent, real-time identification of bacterial pathogens with a metal oxide-based olfactory sensor. Eur J Clin Microbiol 28:775-780

Bunge M, Araghipour N, Mikoviny T, Dunkl J, Schnitzhofer R, Hansel A, Schinner F, Wisthaler A, Margesin R, Märk TD (2008) On-line monitoring of microbial volatile metabolites by proton transfer reaction-mass spectometry. Appl Environ Microb 74:2179-2186

Caldwell BA (2005) Enzyme activities as a component of soil biodiversity: a review. Pedobiologia 49:637-644

Cape JN (2003) Effects of airborne volatile organic compounds on plants. Environ Pollut 122:145-157

Chitarra GS, Abee T, Rombouts FM, Posthumus MA, Dijksterhuis J (2004) Germination of Penicillium paneum conidia is regulated by 1-octen-3-ol, a volatile self-inhibitor. Appl Environ Microbiol 70:2823-2829

Christen P, Bramorski A, Revah S, Soccol CR (2000) Characterization of volatile compounds produced by Rhizopus strains grown on agro-industrial solid wastes. Bioresource Technol 71:211-215

Chuankun X, Minghe M, Leming Z, Keqin Z (2004) Soil volatile fungistasis and volatile fungistatic compounds. Soil Biol Biochem 36:1997-2004

Chung Y-C (2006) Evaluation of gas removal and bacterial community diversity in a biofilter developed to treat composting exhaust gases. J Hazard Mater 144:377-385

Ciani A, Goss K-U, Schwarzenbach RP (2005) Light penetration in soil and particulate minerals. Eur J Soil Sci 56:561-574

Demyttenaere JCR, Moriña RM, DeKimpe N, Sandra P (2004) Use of headspace solid-phase microextraction and headspace sorptive extraction for the detection of the volatile metabolites produced by toxigenic Fusarium species. J Chromatogr A 1027:147-154

Dickschat JS, Helmke E, Schulz S (2005a) Volatile organic compounds from arctic bacteria of the Cytophaga-Flavobacterium-Bacteroides group: a retrobiosynthetic approach in chemotaxonomic investigations. Chem Biodivers 2:318-353

Dickschat JS, Martens T, Brinkhoff T, Simon M, Schulz S (2005b) Volatiles released by a Streptomyces species isolated from the North Sea. Chem Biodivers 2:837-865

Dorman HJD, Deans SG (2000) Antimicrobial agents from plants: antibacterial activity of plant volatile oils. J Appl Microbiol 88:308-316

Duponnois R, Kisa M (2006) The possible role of trehalose in the mycorrhiza helper bacterium effect. Can J Bot 84:1005-1008

European Community (1999) Council directive 1999/13/EC of 11 March 1999 on the limitation of emissions of volatile organic compounds due to the use of organic solvents in certain activities and installations. OJEC, $\mathrm{p} 22$

Ezra D, Jasper J, Todd R, Knighton B, Grimsrud E, Strobel G (2004) Proton transfer reaction-mass spectrometry as a technique to measure volatile emissions of Mucodor albus. Plant Sci 166:1471-1477

Farag MA, Ryu C-M, Sumner LW, Paré PW (2006) GC-MS SPME profiling of rhizobacterial volatiles reveals prospective inducers of growth promotion and induced systemic resistance in plants. Phytochemistry 67:2262-2268

Fernando WGD, Ramarathnam R, Krishnamoorthy AS, Savchuk SC (2005) Identification and use of potential bacterial organic antifungal volatiles. Soil Biol Biochem 37:955-964

Fiddaman PJ, Rossall S (1993) The production of antifungal volatiles by Bacillus subtilis. J Appl Microbiol 74:119-126

Fiedler K, Schütz E, Geh S (2001) Detection of microbial volatile organic compounds (MVOCs) produced by moulds on various materials. Int J Hyg Envir Heal 204:111-121

Fischer G, Dott W (2003) Relevance of airborne fungi and their secondary metabolites for environmental occupation and indoor hygiene. Arch Microbiol 179:75-82

Fischer G, Schwalbe R, Möller M, Ostrowski R, Dott W (1999) Species-specific production of microbial volatile organic compounds (MVOC) by airborne fungi from a compost facility. Chemosphere 39:795-810

Fravel DR, Connick WJ, Grimm CC, Lloyd SW (2002) Volatile compounds emitted by sclerotio of Sclerotinia minor, Sclerotinia 
sclerotiorum, and Sclerotium rolfsii. J Agr Food Chem 50:37613764

Fuchs JG, Bieri M, Chardonnes M (2004) Auswirkungen von Komposten und Gärgut auf die Umwelt, die Bodenfruchtbarkeit sowie die Pflanzengesundheit. Zusammenfassende Übersicht der aktuellen Literautur. Forschungsinstitut für biologischen Landbau. Available via URL http://orgprints.org/2631/01/fuchs-et-al2004-compost-oe.pdf, accessed 7 Sep 2009

Gao P, Martin J (2002) Volatile metabolites produced by three strains of Stachybotrys chartarum cultivated on rice and gypsum board. Appl Occup Environ Hyg 17:430-436

Grabmer W, Graus M, Lindinger C, Wisthaler A, Rappenglück B, Steinbrecher R, Hansel A (2004) Disjunct eddy covariance measurements of monoterpene fluxes from a Norway spruce forest using PTR-MS. Int J Mass Spectrom 239:111-115

Guyot J-P, Brauman A (1986) Methane production from formate by syntrophic association of Methanobacterium bryantii and Desulfovibrio vulgaris. J Appl Environ Microb 52:1436-1437

Han L, Shi X, Wu W, Kirk FL, Luo J, Wang L, Mott D, Cousineau L, Lim SII, Lu S, Zhong C-J (2005) Nanoparticle-structured sensing array materials and pattern recognition for VOC detection. Sensor Acuat 106:431-441

Hansel A, Jordan A, Holzinger R, Prazeller P, Vogel W, Lindinger W (1995) Proton transfer reaction mass spectometry: on-line trace gas analysis at the ppb level. Int J Mass Spectrom 149:609619

Harmsen HJM, VanKuijk BLM, Plugge CM, Akkermans ADL, DeVos WM, Stams AJM (1998) Syntrophobacter fumaroxidans sp. nov., a syntrophic propionate-degrading sulfate-reducing bacterium. Int J Syst Bacteriol 48:1383-1387

Hinton A, Hume ME (1995) Antibacterial activity of the metabolic by-products of a Veillonella species and Bacteroides fragilis. Anaerobe 1:121-127

Höckelmann C, Jüttner F (2004) Volatile organic compound (VOC) analysis and sources of limonene, cyclohexanone and straight chain aldehydes in axenic culltures of Calothrix and Plectonema. Water Sci Technol 49:47-54

Hynes J, Müller CT, Jones HT, Boddy L (2007) Changes in volatile production during the course of fungal mycelial interactions between Hypholoma fascicular and Resinicium bicolor. J Chem Ecol 33:43-57

Insam H (2001) Developments in soil microbiology since the mid 1960s. Geoderma 100:389-402

Isidorov V, Jdanova M (2002) Volatile organic compounds from leaves litter. Chemosphere 48:975-979

Kai M, Effmert U, Berg G, Piechulla B (2006) Volatiles of bacterial antagonists inhibit mycelial growth of the plant pathogen Rhizotonia solani. Arch Microbiol 187:351-360

Kai M, Vespermann A, Piechulla B (2008) The growth of fungi and Arabidopsis thaliana is infuenced by bacterial volatiles. Plant Signal Behav 3:482-484

Kai M, Haustein M, Molina F, Petri A, Scholz B, Piechulla B (2009) Bacterial volatiles and their action potential. Appl Microbiol Biotechnol 81:1001-1012

Karl T, Guenther A, Spirig C, Hansel A, Fall R (2003) Seasonal variation of biogenic VOC emissions above a mixed hardwood forest in northern Michigan. Geophys Res Lett 30:23

Kaufmann K, Chapman SJ, Campbell CD, Harms H, Höhener P (2005) Miniaturized test system for soil respiration induced by volatile pollutants. Environ Pollut 140:269-278

Kershi G, Magan N, Voysey P (1998) Use of an electronic nose for the early detection and differentiation between spoilage fungi. Lett Appl Microbiol 27:261-264

Kesselmeier J, Staudt M (1999) Biogenic volatile organic compounds VOC an overview on emission physiology and ecology. J Atmos Chem 33:23-88
Konstantinou IK, Zarkadis AK, Albanis TA (2001) Photodegradation of selected herbicides in various natural waters and soils under environmental conditions. J Environ Qual 30:121-130

Kreuzwieser J, Cojocariu C, Jüssen V, Rennenberg H (2002) Elevated atmospheric $\mathrm{CO}_{2}$ causes seasonal changes in carbonyl emissions from Quercus ilex. New Phytol 154:327-333

Krzycki JA, Zeikus JG (1984) Acetate catabolism by Methanosarcina barkeri: hydrogen-dependent methane production from acetate by a soluble cell protein fraction. Microbiol Lett 25:27-32

Larsen TO, Frisvad JC (1995a) Chemosystematics of Penicillium based on profiles of volatile metabolites. Mycol Res 99:11671174

Larsen TO, Frisvad JC (1995b) Comparison of different methods for collection of volatile chemical markers from fungi. J Microbiol Methods 24:135-144

Larsen TO, Frisvad JC (1995c) Characterization of volatile metabolites from 47 Penicillium taxa. Mycol Res 99:1153-1166

Leff JW, Fierer N (2008) Volatile organic compound (VOC) emissions from soil and litter samples. Soil Biol Biochem 40:1629-1636

Lindinger W, Hansel A, Jordan A (1998) On-line monitoring fo volatile organic compounds at ppt levels by means of protontransfer-reaction mass spectometry (PTR-MS) medical applications, food control and environmental research. Int $\mathrm{J}$ Mass Spectrom 173:191-241

Linton CJ, Wright SJL (1993) Volatile organic compounds: microbiological aspects and some technological implications. J Appl Bacteriol 75:1-12

Liu W, Mu W, Zhu B, Liu F (2008) Antifungal activities and components of VOCs produced by Bacillus subtilis $\mathrm{G}_{8}$. Curr Res Bacteriol 1:28-34

Mackie AE, Wheatley RE (1999) Effects and incidence of volatile organic compound interactions between soil bacterial and fungel isolates. Soil Biol Biochem 31:375-385

Malhautier L, Khammar N, Bayle S, Fanlo JL (2005) Biofiltration of volatile organic compounds. Appl Microbiol Biotechnol 68:1622

Mattheis JP, Roberts RG (1992) Identification of geosmin as a volatile metabolite of Penicillium expansum. Appl Environ Microbiol 58:3170-3172

Matysik S, Herbarth O, Mueller A (2009) Determination of microbial volatile organic compounds (MVOCs) by passive sampling onto charcoal sorbents. Chemosphere 76:114-119

Mayr D, Margesin R, Klingsbichel E, Hartungen E, Denewein D, Schinner F, Märk TD (2003a) Rapid detection of meat spoilage by measuring volatile organic compounds by using proton transfer reaction mass spectrometry. Appl Environ Microbiol 69:4697-4705

Mayr D, Margesin R, Schinner F, Märk TD (2003b) Detection of the spoiling of meat using PTR-MS. Int J Mass Spectrom 223:229235

Mayrhofer S, Mikoviny T, Waldhuber S, Wagner AO, Innerebner G, Franke-Whittle IH, Märk TD, Hansel A, Insam H (2006) Microbial community related to volatile organic compound (VOC) emission in household biowaste. Environ Microbiol 8:1960-1974

McNeal KS, Herbert BE (2009) Volatile organic metabolites as indicators of soil microbial activity and community composition shifts. Soil Sci Soc Am J 73:579-588

Minerdi D, Bossi S, Gullino ML, Garibalidi A (2008) Volatile organic compounds: a potential direct long-distance mechanism for antagonistic action of Fusarium oxysporum strain MSA 35. Environ Microbiol 11:844-854

Nilsson T, Larsen TO, Montanarella L, Madsen JØ (1996) Application of head-space solid-phase microextraction for the analysis of volatile metabolites emitted by Penicillium species. J Microbiol Methods 25:245-255 
Owen S, Clark S, Pompe M, Semple KT (2007) Biogenic volatile organic compounds as potential carbon sources for microbial communities in soil form the rhizosphere of Populus tremula. FEMS Microbiol Lett 268:34-39

Paavolainen L, Kitunen V, Smolander A (1998) Inhibition of nitrification in forest soil by monoterpenes. Plant Soil 205:147-154

Pasanen A-L, Lappalainen S, Pasanen P (1996) Volatile organic metabolites associated with some toxic fungi and their mycotoxins. Analyst 121:1949-1953

Peladan F, Turlot JC, Monteil H (1984) Discriminant analysis of volatile fatty acids produced in culture medium: a novel approach to the identification of Pseudomonas species. J Gen Microbiol 130:3175-3182

Peñuelas $J$, Llusià $J$ (2001) The complexity of factors driving volatile organic compound emissions by plants. Biol Plant 44:481-487

Pietramellara G, Ascher J, Borgogni F, Ceccherini MT, Guerri G, Nannipieri P (2009) Extracellular DNA in soil and sediment: fate and ecological relevance. Biol Fertil Soil 45:219-235

Rajamäki T, Arnold M, Venelampi O, Vikman M, Räsänen J, Itävaara M (2005) An electronic eose and indicator volatiles for monitoring of the composting process. Water Air Soil Pollut 162:71-87

Roesch LFW, Fulthorpe RR, Riva A, Casella G, Hadwin AKM, Kent AD, Daroub SH, Camargo FAO, Farmerie WG, Triplett EW (2007) Pyrosequencing enumerates and contrasts soil microbial diversity. ISME J 1:283-290

Roose-Amsaleg CL, Garnier-Sillam E, Harry M (2001) Extraction and purification of microbial DNA from soil and sediment samples. Appl Soil Ecol 18:47-60

Ruiz J, Bilbao R, Murillo MB (1998) Adsorption of different VOC onto soil minerals from the gas phase: influence of mineral, type of VOC, and air humidity. Environ Sci Technol 32:1079-1084

Ryu C-M, Farag MA, Hu C-H, Reddy MS, Wei H-X, Paré PW, Kloepper JW (2003) Bacterial volatiles promote growth in Arabidopsis. PNAS 100:4927-4932

Schade GW, Custer TG (2004) OVOC emissions from agricultural soil in northern Germany during the 2003 European heat wave. Atmos Environ 38:6105-6114

Schnürer J, Olsson J, Börjesson T (1999) Fungal volatiles as indicators of food and feeds spoilage. Fungal Genet Biol 27:209-217

Schöller C, Molin S, Wilkins S (1997) Volatile metabolites fom some Gram-negative bacteria. Chemosphere 35:1487-1495

Schöller CEG, Gürtler H, Pedersen R, Molin S, Wilkins K (2002) Volatile metabolites from Actinomycetes. J Agric Food Chem 50:2615-2621

Schulz S, Dickschat JS (2007) Bacterial volatiles: the smell of small organisms. Roy Soc Chem 24:814-842

Seewald MSA (2008) Traceability of compost amendment to soil determined through characterisation of volatile organic compound (VOC) emission patterns. Master thesis, Leopold Franzens University of Innsbruck, p 102

Seewald MSA, Bonfanti M, Singer W, Knapp BA, Hansel A, FrankeWhittle I, Insam H (2010) Substrate induced VOC emissions from compost amended soils under aerobic and anaerobic incubation. Biol Fertil Soils (in press)

Serrano A, Gallego M (2006) Sorption study of 25 volatile organic compounds in several Mediterranean soils using headspace-gas chromatography-mass spectrometry. J Chromatogr 1118:261-270

Smet E, VanLangenhove H, DeBo I (1999) The emissions of volatile compounds during the aerobic and the combined anaerobic/ aerobic composting of biowaste. Atmos Environ 33:12951303

Smolander A, Ketola RA, Kotiaho T, Kanerva S, Suominen K, Kitunen V (2006) Volatile monoterpenes in soil atmosphere under birch and conifers: effects on soil $\mathrm{N}$ transformations. Soil Biol Biochem 38:3436-3442

Spilvallo R, Bossi S, Maffei M, Bonfante P (2007a) Discrimination of truffle fruiting body versus mycelial aromas by stir bar sorptive extraction. Phytochemistry 68:2584-2598

Spilvallo R, Novero M, Bertea CM, Bossi S, Bonfante P (2007b) Truffle volatiles inhibit growth and induce an oxidative burst in Arabidopsis thaliana. New Phytol 175:417-424

Stahl PD, Parkin TB (1976) Microbial production of volatile organic compounds in soil microcosms. Soil Sci Soc Am J 60:821-828

Stams AJM, Plugge CM (2009) Electron transfer in syntrophic communities of anaerobic bacteria and archaea. Nat Rev Micro 7:568-577

Stotzky G, Schenck S (1976) Volatile organic compounds and microorganisms. CRC Crit Rev Microbiol 4:333-382

Strobel GA, Dirkse E, Sears J, Markworth C (2001) Volatile antimicrobials from Muscodor albus, a novel endophytic fungus. Microbiology 147:2943-2950

Strobel GA, Kluck K, Hess WM, Sears J, Ezra D, Vargas PN (2007) Muscodor albus E-6, an endophyte of Guazuma ulmifolia making volatile antibiotics: isolation, characterization and experimental establishment in the host plant. Microbiology 153:2613-2620

Sunesson A-L, Vaes WHC, Nilsson C-A, Blomquist G, Andersson B, Carlson R (1995) Identification of volatile metabolites from five fungal species cultivated on two media. Appl Environ Microbiol 61:2911-2918

Tholl D, Boland W, Hansel A, Loreto F, Röse USR, Schnitzler J-P (2006) Practical approaches to plant volatile analysis. Plant J 45:540-560

Turan N, Akdemir A, Ergun O (2007) Emission of volatile organic compounds during composting of poultry litter. Water Air Soil Pollut 184:177-182

Vergnais L, Masson F, Montel MC, Berdague JL, Talon R (1998) Evaluation of solid-phase microextraction for analysis of volatile metabolites produced by Staphylococci. J Agric Food Chem 46:228-234

Vespermann A, Kai M, Piechulla B (2007) Rhizobacterial volatiles affect the growth of fungi and Arabidopsis thaliana. Appl Environ Microbiol 73:5639-5641

Wang X, Wu T (2008) Release of isoprene and monoterpenes during the aerobic decomposition of orange wastes from laboratory incubation experiments. Environ Sci Technol 42:3265-3270

Ward BB, Courtney KJ, Langenheim JH (1997) Inhibition of Nitrosomonas europaea by monoterpenes from coastal redwood (Sequoia sempervirens) in whole-cell studies. J Chem Ecol 23:2583-2598

Wenke K, Kai M, Piechulla B (2010) Belowground volatiles facilitate interactions between plant roots and soil organisms. Planta 231:499-506. doi:10.1007/s00425-009-1076-2

Wheatley RE (2002) The consequences of volatile organic compound mediated bacterial and fungal interactions. Anton Leeuw J Microb 81:357-364

Wheatley RE, Millar SE, Griffiths DW (1996) The production of volatile organic compounds during nitrogen transformation in soils. Plant Soil 181:163-167

Wheatley R, Hackett C, Bruce A, Kundzewicz A (1997) Effect of substrate composition on production of volatile organic compounds from Trichoderma spp. Inhibitory to wood decay fungi. Int Biodeterior Biodegrad 39:199-205

Wilkins K, Parkkalle L (1996) Volatile metabolites from actinomycetes. Chemosphere 32:1427-1434

Wilkins K, Larsen K, Simkus M (2000) Volatile metabolites from mold growth on building materials and synthetic media. Chemosphere 41:437-446 
Willson SC, Jones KC (1996) The fate and behavior of volatile aromatic hydrocarbons in sewage sludge-amended soil. ASTM Spec Tech Publ 1261:119-123

Wood S, Williams ST, White WR (1985) Potential sites of geosmin production by Streptomycetes in and around reservoirs. J Appl Microbiol 58:319-326

Wood S, Williams ST, White WR (2001) Microbes as as source of earthy flavours in potable water-a review. Int Biodeterior Biodegrad 48:26-40

Woolley JT, Stoller EW (1977) Light penetration and light-induced seed germination in soil. Plant Physiol 61:597-600
Zeringue HJ Jr, Bhatnagar D, Cleveland TE (1993) $\mathrm{C}_{15} \mathrm{H}_{24}$ volatile compounds unique to aflatoxigenic strains of Aspergillus flavus. Appl Environ Microbiol 59:2264-2270

Zhang H, Kim MS, Krishnamachari V, Payton P, Sun Y, Grimson M, Farag MA, Ryu C-M, Allan R, Melo IS, Paré PW (2007) Rhizobacterial volatile emissions regulate auxin homeostasis and cell expansion in Arabidopsis. Planta 4:839-851

Zou C-S, Mo M-H, Gu Y-Q, Zhou J-P, Zhang K-Q (2007) Possible contributions of volatile-producing bacteria to soil fungistasis. Soil Biol Biochem 39:2371-2379 